\title{
The relationship between person-organization fit and job satisfaction
}

\author{
Pei Chen, ${ }^{1}$ Paul Sparrow, ${ }^{2}$ Cary Cooper ${ }^{3}$ \\ ${ }^{1}$ Southwestern University of Finance and Economics, Sichuan Ctiy, China, ${ }^{2}$ Lancaster University, Lancaster, UK, \\ and ${ }^{3}$ Manchester University, Manchester, UK \\ Purpose - Drawing upon the theory of conservation of resources to argue the importance of job stress as an important
} variable that mediates the person-organization fit (P-O fit)-job satisfaction relationship, and supervisor support as an important moderating variable that moderates the relationship between P-O fit and job stress, this study tests a moderated mediation model.

Design/methodology/approach - Data were collected from 225 employees in twelve catering service organizations in Beijing. An integrated mediation and moderation model was evaluated.

Findings - The study illustrates both some new mechanisms and the boundary conditions between P-O fit and job satisfaction. Job stress mediates the relationships between person-organization fit and job satisfaction; supervisor support moderates the linkage of P-O fit, job stress and job satisfaction. The corresponding moderated mediation model was supported.

Research limitations/implications - The question of causality cannot be determined because of the cross-sectional research design; Self-report is a necessary strategy for the assessment of subjects' appraisals. However, it requires some caution in interpreting the results.

Practical implications - The findings offer a better understanding of the way P-O fit is able to affect job satisfaction. Actions designed to promote P-O fit may be useful in reducing employees’ stress and result in higher job satisfaction. To enhance the relationships between P-O fit and employees' job satisfaction through supervisor support, supervisors should develop a positive form of reciprocation by helping employees to solve the real problem they are facing.

Originality/value - No previous studies have investigated influencing factors of employees' satisfaction from the perspective of individual and organizational interfaces.

Keywords: Service industry, Person-organization fit, Job satisfaction, Stress, Mediation, Moderation 
The increased recognition of employees as a critical resource in the global marketplace has sustained academic interest on the effects that person-organization (P-O) fit has on employee work attitudes and behavior (Hoffman \& Woehr, 2006, Cooper-Thomas \& Wright, 2013, Peng, Lee, \& Tseng, 2014). P-O fit pertains to a match between individual and organizational characteristics (George, 1992; Kristof, 1996). Achieving a high degree of P-O fit is seen as key in retaining workforces with high flexibility and the organizational commitment necessary to meet competitive challenges. Consequently, in P-O fit studies, work attitudes (defined as evaluative tendencies toward one’s job) such as job satisfaction, organizational commitment and turnover intention are among the outcomes most frequently examined (Verquer, Beehr, \& Wagner, 2003; Silverthorne, 2004; Ambrose, Arnaud, \& Schminke, 2008).

We know from prior research that P-O fit bears a relation to stress. Person-environment (P-E) fit theory posits that stress arises from a poor match between characteristics of the individual employee and of the job situation. Edwards (1996) examined two types of personenvironment (P-E) fit on stress, one representing the fit between environmental supplies and employee values (S-V fit), and another the fit between environmental demands and employee abilities (D-A fit). His results indicated that S-V fit was linked primarily to dissatisfaction, DA fit was linked to tension, but both types of fit were related to both forms of strain. We also know that stress bears a relationship to job satisfaction. Arthur, Bell, Villado and Doverspike (2006) noted that little is known about the mechanisms that underpin P-O fit's demonstrated influence on job satisfaction. Ahsan, Abdullah, Fie, and Alam (2009) investigated the relationship between job stress and job satisfaction. The results showed that there is a significant negative relationship between job stress and job satisfaction. Klassen, Usher, and Bong (2010) revealed that job stress was negatively related to job satisfaction for North American teachers. P-O fit researchers have tested the P-O fit-job stress and P-O fit-job satisfaction relationships independently, instead of concurrently. We argue that in order to 
build upon the argument that P-O fit predicts job satisfaction, P-O fit researchers must now simultaneously examine the combined effects of P-O fit and job stress on job satisfaction.

Fit theorists continue to call for research to incorporate important situational characteristics that can moderate fit-outcome relationships (Kristof-Brown, Zimmerman, \& Johnson, 2005; Erdogan \& Enders, 2007; Park, Monnot, Jacob, \& Wagner, 2011). Subsequent empirical studies about moderation effects are few in number, but have predominantly looked at the moderating effects of individual differences (Resick, Baltes, \& Shantz, 2007; Park, Monnot, Jacob, \& Wagner, 2011). However, these studies have still not assessed the role of important organizational moderators, and yet it is the management of these moderators that enables organizations to enhance organizational membership if there is low P-O fit.

In the present study, we focus on an important (and manageable) organizational moderator by examining the situational variable of supervisor support. There is good reason to believe that this factor has an important impact on the P-O fit -stress- job satisfaction relationship. Studies show that person-organization fit perceptions are related to perceived organizational support (Hutchison, Sowa, Eisenberger, \& Huntington, 1986), and that supervisors are considered agents of the organization. We also know that their treatment of subordinates can influence how subordinates perceive their relationship with the organization (Eisenberger, Stinglhamber, Vandenberghe, Sucharski, \& Rhoades, 2002). It is reasonable to assume that supervisor support could have an important moderating impact in the link between P-O fit and its outcomes, yet surprisingly this has received little study in the literature. We build on this argument in the literature review section.

Whilst our predictors of P-O fit are not assumed to be culture-bound they need to be studied in a setting where our moderator and mediator variables are likely both to be evidenced, and to be of consequence. The sectoral context for our study is the service industry - specifically the hospitality sector. In this sector increasing employees' job 
satisfaction has been shown to contribute to increased competitiveness of the organization (Nadiri \& Tanova, 2010). The sector can also be associated with limited decision latitude, frequent exposure to customer complaints, and other work-related characteristics that are likely to make employees highly susceptible to elevated levels of job stress (PapadopoulouBayliss et al., 2001). Supervisor support should be expected to enable employees to make decisions that enhance the service expectations of their guests. The national context is that of China. The majority of research on P-O fit has been in western settings, and whilst not a specific aim of this study, research in different cultural settings is necessary in order to assess the generalizability of P-O fit theory (Zhong \& Lin, 2010).

Our research then examines the relationship between the following variables: P-O fit, supervisor support, job stress and job satisfaction, under a single model, in order to make clear the relationships between them.

\section{Literature review and hypotheses}

P-O fit on job satisfaction

Researchers can examine "fit" across a number of dimensions. The use of values has been seen as the most suitable way of operationalizing fit, because values constitute a reliable guide to understanding a wide range of subsequent work attitudes and behavior. . O'Reilly III, Chatman, and Caldwell (1991) demonstrated that this fit between an individual's preference for a particular culture and the culture of the organization the person joins, is related to commitment, satisfaction, and turnover. Vancouver and Schmitt (1991) investigated relationships between organization members' agreement on organizational goals and its impact on their attitudes and intentions. Using data from 356 principals and 14,721 teachers, each rating the importance of goals for their school, they found goal congruence was 
positively related to job satisfaction. By the early 2000s, there was sufficient evidence to test the strength of such effects. Verquer, Beehr, and Wagner (2003) conducted a meta-analytic review of 21 studies on the relationship between P-O fit and job satisfaction, organizational commitment, and turnover intention. They found mean correlations in the mid to high $0.20 \mathrm{~s}$ for P-O fit with satisfaction and commitment, while the mean effect size between P-O fit and turnover intention was -0.18 . The first hypothesis in our model is necessarily confirmatory:

H1. Person-organization fit is positively related to employees' job satisfaction.

\section{Job stress's mediating effect}

There is empirical evidence that P-O fit is related to job stress and that job stress in turn is related to job satisfaction. This of course does not automatically mean that job stress is the mediator between P-O fit and job satisfaction. We therefore now posit a mechanism by which job stress should be expected to act as a mediator and do this by drawing upon the theory of conservation of resources (COR). COR theory proposes that individuals are motivated to acquire and maintain resources and that what they find threatening is the potential or actual loss of these valued resources (Hobfoll, 2002; Viswesvaran, Sanchez, \& Fisher, 1999). Psychological stress is therefore defined as a reaction to the environment in which there is (a) the threat of a net loss of resources, (b) the net loss of resources, or (c) a lack of resource gain following the investment of resources. Either perceived and actual loss, or lack of gain, is sufficient for producing stress. P-O fit, acting as a kind of social support, provides resources for employees which, in turn, serve to reduce stress. Therefore, we postulate our second hypothesis: 
H2. Job stress mediates the relationships between P-O fit and job satisfaction.

\section{Supervisor support's moderating effect}

Employees prefer and attach great importance to the feedback and support from people close to them (Kottke \& Sharafinski, 1988). Our model incorporates employee experiences of supervisor support. This refers to the extent to which employees perceive supervisors offer them support, encouragement and concern (Burke, Borucki, \& Hurley, 1992). The moderating role of supervisor support in the link between P-O fit and its outcomes is far less studied in the literature, and we believe its inclusion can not only make an interesting contribution to the literature, but is necessary to capture an important explanator of the process. On the one hand, for employees, a body of research has shown that when employees feel supported by an organization, they will reciprocate by demonstrating positive work attitudes and behaviours toward the organization (Eisenberger, Armeli, Rexwinkel, Lynch, \& Rhoades, 2001; Rhoades \& Eisenberger, 2002). On the other hand, for guests, supervisor support, such as empowerment, allows the employees to make important decisions that enhance the service expectations of their guests. Therefore, it is important to study the moderating role of supervisor support, especially in the hospitality sector.

Again, using COR theory, we propose that supervisor support buffers any potential misfit between a person and an organization. Early studies showed that the support and backing of a supervisor, depends on whether or not they give thoughtful consideration, feedback promptly, and are believed to be helpful for employees to overcome work-related problems (Janssen \& Van Yperen, 2004). Supervisor support, as a form of social support, can be seen as a situational resource (Brotheridge \& Lee, 2002). Whilst supervisor undermining behaviour co-exists with supervisor support, it is undermining behaviour that hinders the 
ability of an employee to attain instrumental goals. The opposite to such behaviour (instrumental and socio-emotional support given by the supervisor) is the personal resource. Person-organization fit perceptions also serve as a gauge of an individual's resource capacity for coping with stressful job demands (Babakus, Yavas, \& Ashill, 2010). Therefore, with higher P-O fit, employees can have more resource capacity to tackle stresses that might otherwise limit job satisfaction. We propose that the moderation effect operates as follows. When employees receive high supervisor support, they understand this to be a resource gain, and are more likely, through the role of supervisors as sense-makers, to attribute positive motives to the practices and policies of the organization with regard to them. However, when employees receive low supervisor support (perceived as a net loss of otherwise important resources), they will attribute negative motives to the practices and policies of the organization with regard to them, or may doubt whether they can trust and build a long term relationship with the organization, even if they have high value congruence with it. Supervisor support has also been shown to reduce the strains experienced, mitigate perceived stressors, and moderate the stressor-strain relationship (Viswesvaran, Sanchez, \& Fisher, 1999). Even where P-O fit and supervisor support are relatively high, we should expect that the formation of higher supervisor support enhances the positive influence of high P-O fit with the result of lower job stress. Therefore, we put forward our third hypothesis:

H3. Supervisor support moderates the relationship between P-O fit and job stress, such that higher supervisor support can enhance the positive influence of high $\mathrm{P}-\mathrm{O}$ fit with a result of the lower job stress.

\section{Generalized model}


We now explain the relationships among our research variables by differentiating the moderated mediation model and the mediated moderation model as follows. A moderated mediation model implies that either the effect from independent variable to mediation depends on the moderator, and/or the partial effect of the mediator on the outcome variable, depends on the moderator (Muller, Judd, \& Yzerbyt, 2005). An alternative is a mediated moderation model. This implies there is overall moderation, produced by the mediating process, and when this process is controlled, the residual moderation of the independent variable's effect is reduced compared to the moderation of the overall independent variable's effect (Muller, Judd, \& Yzerbyt, 2005).

Combining our Hypotheses 2 and 3 together, it is evident that the mediating process that intervenes between the P-O fit (independent variable) and job satisfaction (outcome variable) is different for the value of supervisor support (moderator). Based on our previous analysis, we propose a moderated mediation model containing both mediation and moderation effects and examine a series of relationships between our variables. We propose that there is an indirect effect of P-O fit (independent variable) on satisfaction via job stress (as the mediator) and that this is moderated by supervisor support (moderator). In other words, the mediating process that is responsible for producing the effect of P-O fit on job satisfaction (outcome variable) depends on the value of supervisor support (moderator).

H4. Supervisor support moderates the relationship between P-O fit and job stress, such that the positive relationship between high $\mathrm{P}-\mathrm{O}$ fit and job satisfaction through job stress is stronger for employees who have higher supervisor support. 
The complete model for this research is shown in Figure 1.

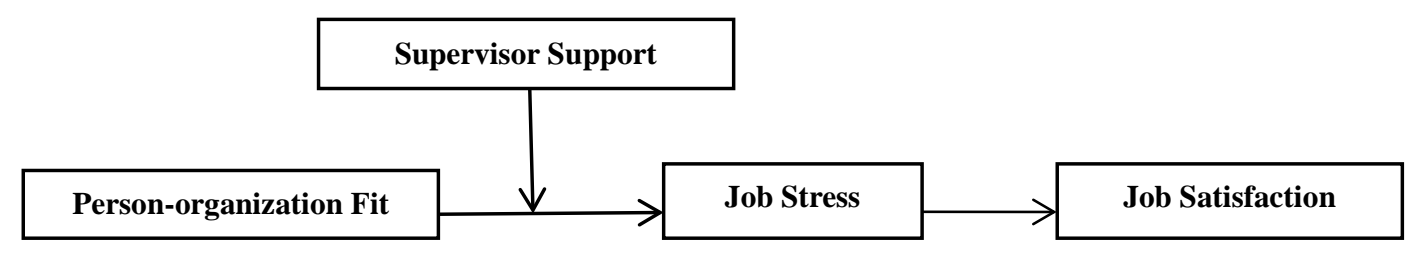

Figure 1. Research model diagram

\section{Research method}

\section{Sample and procedure}

Data were collected from employees in twelve catering service organizations in Beijing. The different organizations are similar to each other in terms of business model and culture, and also in respect of guest flows, annual turnover, and number of employees. Meetings were scheduled to inform employees about the general purpose of the study, to emphasize confidentiality, and to administer questionnaires. Questionnaires were completed during working hours. The final sample consisted of 225 employees with a response rate of $83 \%$. 33\% were male, on average 22.9 years old, with an average of 11.9 months dyadic tenure with their immediate supervisors. $4 \%$ of respondents had obtained a bachelor degree or above, $16 \%$ had a technical college diploma, and the rest had completed senior high degree or below.

\section{Measures}

We created a Chinese version of all the measures by following the translation-backtranslation procedure. For each item, the response was recorded on a six-point Likert scale, ranging from 1 (strongly disagree) to 6 (strongly agree) with the exception of demographic variables.

P-O fit. P-O fit was measured using a nine-item scale developed by Cable and Derue 
(2002). Example items included: "The match is very good between the demands of my job and my personal skills”, “My personal values match my organization’s values and culture”. Cronbach’ s alpha was 0.83.

Supervisor support. The supervisor support scale used in the study is from the Chinese Version of the Job Content Questionnaire (Karasek, Brisson, Kawakami, Houtman, Bongers \& Amick, 1998), the C-JCL, which has been shown to be reliable and valid for assessing psychosocial work conditions among Taiwanese workers (Cheng, Luh, \& Guo, 2003). Four items, which cover two aspects of instrumental and socio-emotional support, are: "My supervisor gives concerns to staff’s welfare”, “My supervisor listens to my opinions”, “My supervisor provides assistance to staff”, "My supervisor organizes well the staff members as to facilitate tasks at work’'. These serve as a single dimension. Cronbach’s alpha was 0.82 .

Job stress. Given our sectoral context, the service industry - hospitality sector, we think a sector-relevant measure of stress is the most appropriate to use. Moreover, given that we use the Conservation of Resource Theory to demonstrate individuals' stress, we needed an instrument that is consistent with Parker and Decotiis (1983)'s stress theory and measure. We adopted the scale developed by Parker and Decotiis (1983) originally used to survey managers of a large restaurant chain. This consisted of thirteen items. Example items included "many people at my level in the company get burned out by job demands", “Working here leaves little time for other activities”. Cronbach’s alpha was 0.86.

Job satisfaction. The scale for measuring job satisfaction consisted of six items taken from Tsui, Egan, and O'Reilly (1991). The Cronbach’s alpha in the original research was 0.83. Exploratory factor analysis ( $\mathrm{Li}, 2003$ ) showed that the employee satisfaction questionnaire had a one-dimensional structure. The extracted factors used in the subsequent analysis explained $44 \%$ of the total variance. Example items included "I am satisfied with the opportunities which exist in this organization for advancement (promotion)?”, “I am satisfied 
with my relations with others in the organization with whom I work.” In consideration of potential localisation issues we tested for Cronbach’s alpha on our sample, which was 0.85.

Control variables. To examine the independent variables' unique contributions in predicting the mediator and outcome variables, we measured and controlled for the effects of participants’ gender (Lok \& Crawford, 2004), age (Lok, \& Crawford, 2004), education (Lok, \& Crawford, 2004) and tenure (Bedeian, Ferris, \& Kacmar, 1992).

\section{Analyses and Results}

\section{Descriptions and correlations}

Means, standard deviations and correlations among variables and inter-correlations among variables are presented in Table 1.

Table 1. Means, standard deviations, and correlations of research variables

\begin{tabular}{|c|c|c|c|c|c|c|c|}
\hline Variables & M & $\mathrm{SD}$ & 1 & 2 & 3 & 4 & 5 \\
\hline 1.Gender & 1.67 & 0.47 & & & & & \\
\hline 2.Age & 1.57 & 0.72 & -0.04 & & & & \\
\hline 3.Education & 2.30 & 1.21 & -0.10 & -0.04 & & & \\
\hline 4.Tenure & 1.90 & 1.16 & 0.13 & 0.07 & -0.03 & & \\
\hline 5.Supervisor support & 4.71 & 0.88 & -0.02 & -0.10 & -0.08 & -0.06 & $(0.82)$ \\
\hline 6.Job satisfaction & 4.05 & 1.02 & 0.01 & -0.00 & $-0.26^{* *}$ & -0.13 & $0.51^{* *}$ \\
\hline 7.Job stress & 3.49 & 0.91 & 0.09 & 0.10 & $0.17^{*}$ & $0.19 * *$ & $-0.24 * *$ \\
\hline 8.P-O fit & 3.91 & 0.81 & 0.06 & -0.02 & -0.03 & -0.01 & $0.38 * *$ \\
\hline
\end{tabular}

Notes: $n=225$.Tenure was measured by the tenure with the current immediate supervisor. The reliability coefficients appear in parenthe 0.01 (2-tailed)

\section{Common method bias}

Since we collected self-report data, to examine whether common method bias influenced our study, we conducted the Harman's single-factor test. This requires loading all the measures in a study into an exploratory factor analysis, with the assumption that the presence of common method variance (CMV) is indicated by the emergence of either a single factor or a general 
factor accounting for the majority of covariance among measures (Podsakoff et al. 2003). By conducting factor analysis with no rotation, we found that a four-factor model may be the most appropriate rather than single-factor one. The first factor explained 25.64\% covariance.

To further verify the discrimination of our scales, we conducted confirmatory factor analyses for our four study variables. A four-factor model had a satisfactory fit (CFI=0.80; TLI=0.80; RMSEA=0.08). In contrast, a one-factor model fitted the data significantly worse (CFI=0.46; TLI=0.43; RMSEA=0.13). Thus, the CFA supports the discriminant validity of our scales and we believe that CMV is not a serious problem in this study.

\section{Mediation hypothesis test}

To test the mediation hypothesis, we adopted the procedure proposed by Preacher and Hayes (2008). Independent variables should be significantly related to mediation variables, and after controlling for the effect of independent variables, mediation variables should be significantly related to dependent variable. An important indication of mediation within the analysis of Preacher and Hayes is the significance level of the indirect effect from P-O fit to job satisfaction through job stress, as indicated by the p-value or the bias corrected bootstrap intervals. To respond to the normal distribution hypothesis, we adopted bootstrapping method. The SPSS macro PROCESS was utilized to conduct the analyses.

As the results showed, $\mathrm{P}-\mathrm{O}$ fit was significantly related to job stress $(\beta=-0.19, p<0.05$, 95\% CI $=[-0.33,-0.04])$. And when P-O fit was controlled, job stress was still significantly related to job satisfaction $(\beta=-0.39, p<0.001,95 \% C I=[-0.52,-0.26])$. When job stress was entered, the indirect effect from P-O fit to job satisfaction was significant, with 95\% CI being $[0.01,0.16]$. While the direct effect was still significant, with 95\% CI being [0.34, 0.61]. Therefore, we could conclude that job stress partially mediate the relationship between P-O 
fit and job satisfaction.

\section{Moderated mediation hypothesis test}

Since we proposed that the mediating process that is responsible for producing the effect of the P-O fit (independent variable) on job satisfaction (outcome variable) depends on the value of supervisor support (moderator), we confirmed it is a moderated mediation model. According to Preacher, Rucker and Hayes (2007), three steps are essential to test a moderated mediation model. First, we should examine the mediation variable model with mediator variable as dependent variable, and in this equation the interaction variable should be significant. In other words, the simple moderation should be significant. Next, we should examine the dependent variable model with outcome variable as dependent variable. After the two steps, we could calculate out the indirect effect, and see whether the indirect effect was dependent on the moderation variable. The SPSS macro PROCESS was utilized, and model 7 was adopted. The results were showed at Table 2 .

The significance of the effect of the interaction variable toward job stress was satisfactory $(\beta=0.12, p=0.08<0.1,95 \% C I=[-0.02,0.25])$ since PROCESS includes a bias corrected confidence interval per indirect effect; thus, providing more information about the statistical significance. Although the direct effect remained significant, the strength of the indirect effect was dependent on the level of supervisor support (moderator). Further analysis showed that at different value of the moderator, the indirect effect varied. For example, at the standard deviation below the mean value of supervisor support, the indirect effect was 0.08 , with bootstrapping 95\% CI being $[0.01,0.14]$. Thus, we think we can conclude that the moderated mediation model was supported.

To further examine the patterns of interaction, we plotted the interactive effect figure 
based on the procedures introduced by Akien and West (1991).

Table 2. Bootstrapping with moderated mediation model

\begin{tabular}{|c|c|c|c|c|c|c|}
\hline Variable & $B$ & $S E$ & $t$ & $P$ & $L L C I$ & $U L C I$ \\
\hline \multicolumn{7}{|c|}{ Mediator variable model with job stress as dependent variable } \\
\hline Constant & -0.45 & 0.21 & -2.10 & 0.04 & -1.87 & -0.03 \\
\hline P-O fit & -0.09 & 0.08 & -1.18 & 0.24 & -0.25 & 0.06 \\
\hline Supervisor support & -0.19 & 0.07 & -2.61 & 0.01 & -0.34 & -0.05 \\
\hline Interaction variable $(\mathrm{P}-\mathrm{O}$ fit $\times$ Supervisor support) & 0.12 & 0.07 & 1.71 & 0.08 & -0.02 & 0.25 \\
\hline Gender & 0.25 & 0.12 & 2.03 & 0.04 & 0.01 & 0.49 \\
\hline Age & 0.04 & 0.08 & 0.51 & 0.61 & -0.12 & 0.20 \\
\hline Education & 0.13 & 0.05 & 2.62 & 0.01 & 0.03 & 0.22 \\
\hline Tenure & 0.11 & 0.05 & 2.18 & 0.03 & 0.01 & 0.21 \\
\hline \multicolumn{7}{|c|}{ Dependent variable model with job satisfaction as dependent variable } \\
\hline Constant & 4.24 & 0.29 & 14.65 & 0.00 & 3.67 & 4.81 \\
\hline Job stress & -0.39 & 0.07 & -6.03 & 0.00 & -0.52 & -0.26 \\
\hline P-O fit & 0.48 & 0.07 & 6.81 & 0.86 & 0.34 & 0.61 \\
\hline Gender & 0.05 & 0.12 & 0.41 & 0.00 & -0.19 & 0.29 \\
\hline Age & 0.04 & 0.08 & 0.51 & 0.56 & -0.12 & 0.20 \\
\hline Education & -0.12 & 0.05 & -2.51 & 0.96 & -0.21 & -0.03 \\
\hline Tenure & -0.03 & 0.05 & -0.62 & 0.77 & -0.13 & 0.07 \\
\hline \multicolumn{7}{|c|}{ Conditional indirect effect as a function of supervisor support } \\
\hline Value of supervisor support & & Effect & Bootse & Boot LLCI & & BootULCI \\
\hline-0.88 & & 0.08 & 0.03 & 0.01 & & 0.14 \\
\hline 0.00 & & 0.04 & 0.03 & -0.02 & & 0.10 \\
\hline 0.88 & & -0.00 & 0.04 & -0.08 & & 0.09 \\
\hline
\end{tabular}




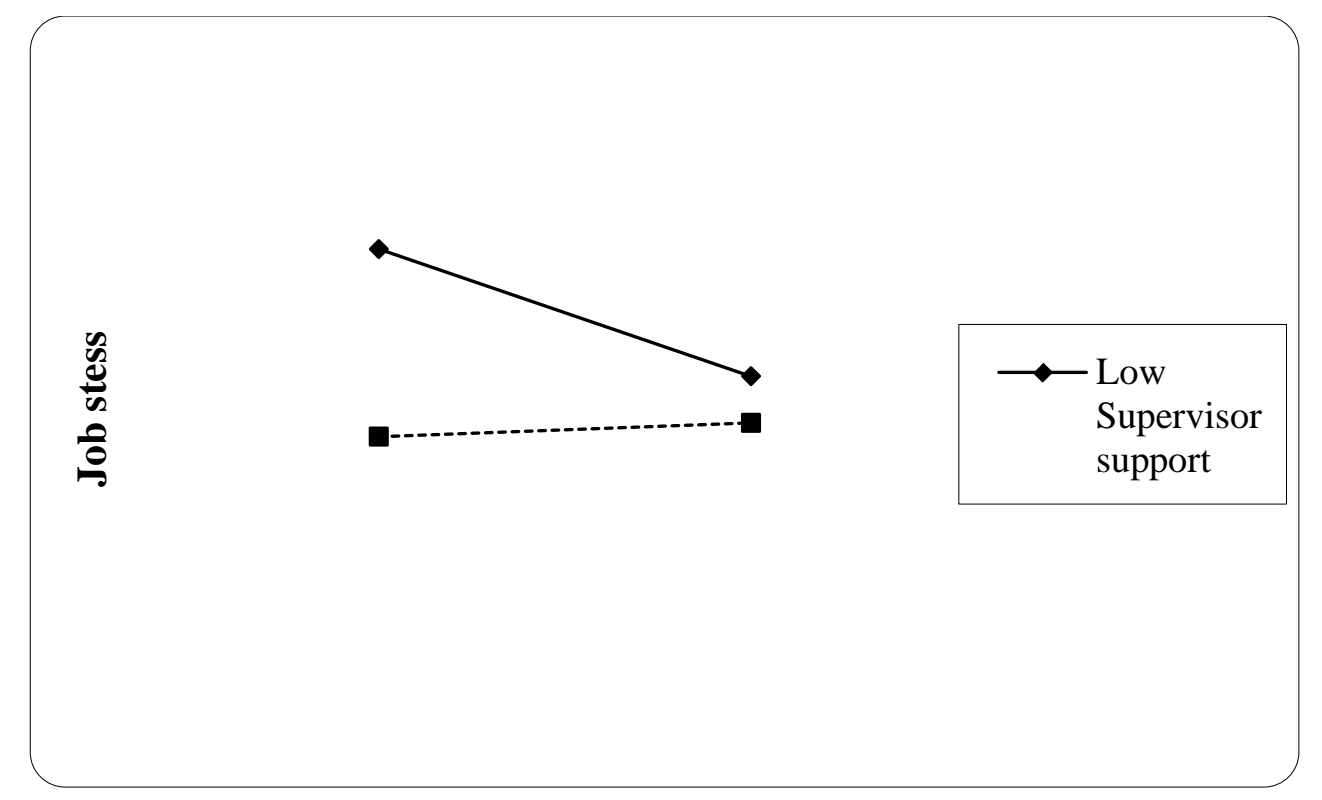

Figure 2. The moderation effect of supervisor support (Moderator) between P-O fit (IV) and job stress (DV)

\section{Discussion}

As expected and demonstrated, P-O fit is related to the organizationally relevant outcome of job satisfaction (Cooper-Thomas et al., 2004; Westerman \& Cyr, 2004). Our research confirms that P-O fit positively predicts job satisfaction; but importantly then shows that job stress mediates this relationship. This is consistent with the widely accepted P-E fit approach to stress among organizational stress researchers (Eulgberg, Weekley, \& Bhagat, 1988). Therefore, high P-O fit can improve an employees' working state, which is also the primary premise and management foundation for building a harmonious organization.

Our research further reveals some boundary conditions for the mechanism of P-O fit. We found that supervisor support moderates the relationship between P-O fit and job stress as we previously assumed. Consistent with the conservation of resources theory, results indicate that when an employee is adversely affected by low P-O fit, support from the supervisor which could be perceived as a resource is especially important in the reduction of job stress. 
Finally, Silverthorne's P-O fit research results indicate that the degree of P-O fit plays an important role in all of the types of organizational culture studied (Silverthorne, 2004). Our results also indicate that the $\mathrm{P}-\mathrm{O}$ fit is an important variable within the organizations in non-western cultures. The underlying mechanism and conditional effect study between these two variables provides important evidence for improving employees' job satisfaction in China.

\section{Theoretical implications}

Our study provides important theoretical contributions to the literature on P-O fit, job satisfaction, job stress, and supervisor support.

Firstly, it shows that the relationship between P-O fit and job satisfaction is indirectly linked through job stress. Our results can be illustrated by the COR theory. A tenet of COR theory is that individuals try to protect and conserve "things" they value (Hobfoll, 2001). Perceived P-J fit serves as a gauge of an individual's resource capacity for coping with stressful job demands. Therefore, with the higher P-O fit, employees can have more resource capacity to tackle stresses which lead to higher job satisfaction. Our finding integrates COR theory (Hobfoll, 2001) into our understanding of the process linking P-O fit to employee work attitude. The positive impact of P-O fit on job satisfaction reinforces the findings from earlier research (Silverthorne, 2004; Kristof-Brown et al., 2005; Liu, Liu \& Hu, 2010). This also indicates $\mathrm{P}-\mathrm{O}$ fit is an important variable within the organizations in non-western cultures.

Another important contribution of our findings is the existence of a moderating role of supervisor support in the relationship of $\mathrm{P}-\mathrm{O}$ fit and job stress, and the positive relationship between high P-O fit and job satisfaction through job stress is stronger for employees who 
have higher supervisor support. Since turnover results from a lack of job satisfaction and turnover causes significant expense to an organization, this interaction has important implications for organizations (Tett \& Meyer, 1993). Supervisor support is valuable resources and can serve as direct antidotes to burnout (Lee \& Ashforth, 1996). Our results are in line with our hypotheses in the sense that people experience most job stress when they experience low fit and experience no supervisor support. Having supervisor support in the case of low fit can clearly decrease the level of stress. When supervisor support is low, P-O fit has a negative relationship with job stress; when supervisor support is high, P-O fit has a nonsignificant relationship with job stress. This means that P-O fit is not related to job stress as long as the supervisor supports the employees. These results are in line with the reasoning of the paper and in line with COR theory. Only through effective relationships with leaders, organizations may eliminate the negative effects of low value congruence (Erdogan, Kraimer, \& Liden, 2004). The study has addressed the call for research examining new mechanisms and boundary conditions between P-O fit and job satisfaction.

\section{Practical implications}

The research explores influencing factors of employees' satisfaction in a Chinese context from the perspective of individual and organizational interfaces. This provides empirical evidence that organizations can have a positive influence on followers, especially in terms of reducing their job stress and enhancing followers’ satisfaction.

Specifically, since the impact of fit on job satisfaction indicates that the degree of fit plays an important role, organizations could invest in modifying selection systems so that individuals have more fit with those of the organization are hired, or underscore and validate the adoption of culture training which can promote individuals in strengthening learning in all 
aspects of organization environment, including policy history, proficient work, organizational objectives, values, etc., thus realise more fit between individuals and organizations (Cennamo \& Gardner, 2008). More importantly, to the extent that job stress mediates the relationship between P-O fit and job satisfaction, taking steps to reduce employee job stress by eliminating or reducing workplace stressors, such as redesigning the task, redesigning the work environment, establishing fair employment policies, etc. (Elkin \& Rosch, 1989) would be positively associated with desired organizational outcomes, and reduce the impact of P-O incongruence at the same time.

\section{Limitation and future research direction}

Despite the promising findings of this paper, there are some limitations associated with the current research that should be addressed in future work.

Firstly, the cross-sectional design of the present study did not allow us to determine the direction of causality among the variables. Whilst there are natural limitations as to what might be achieved with a cross sectional design, we point to the importance of the new variables being introduced to the model, which have not been subject to significant prior study in the relationships being examined. In our problematisation of the field, we have shown that, surprisingly, the impact of P-O fit on job satisfaction has not really been examined in parallel to another important outcome, which is that of stress, nor has the potential role of supervisor support been set against these two outcomes. A more exploratory design is appropriate, especially as the analysis raises some important and surprising findings, for example suggesting that COR theory might be overly simplistic as a framework in some areas, notably to capture the role that supervisory support might have. This said, future research should now consider the influence of P-O fit, and supervisory support, on our 
outcomes over a period of time. P-O fit is a two-way adaptation and coordination between individual and organization as two entities with increasing service and working time. Thus the compatibility of both is not static nor remains the same, but is dynamic. With a crosssectional design we have been able to examine a series of relationships to support our proposed model, but a longitudinal research approach would make additional contributions to our understanding of their development over time, and their causal sequence. Our design has enabled us to demonstrate that supervisory support might work in complex ways, contrary to theoretical expectations, and our datapoint signals that this issue merits more focused examination.

Secondly, whilst self-report is a necessary strategy for the assessment of subjects' appraisals clearly, it would be desirable to include objective measures of job stress or multisource ratings of P-O fit (e.g. co-worker, supervisor). Some statistical caution in interpreting the results of any self report data, as both quadratic and interaction terms can be severely deflated through CMV, making them more difficult to detect through statistical means (Siemsen, Roth, \& Oliveira, 2010). On the job stress scale, the correlation between two factors (time stress and anxiety) was 0.54, indicating non-overlapping variance in the dimensions (Parker \& Decotiis, 1983). Future researchers may choose to treat these dimensions (time stress and anxiety) separately.

\section{Conclusion}

This study has tested an integrated mediation and moderation model of the relationship between P-O fit and job satisfaction. We integrated the theory of conservation of resources into our understanding of the process of linking P-O fit to employee work attitudes. Evidence was found for a mediating role of job stress in the relationship between P-O fit and job 
satisfaction and for a moderating role of supervisor support in this relationship. These results expand current knowledge regarding the relationship between P-O fit and outcomes. It is important that HR practices choose qualified employees based on the assessment of their fit or help employees to meet the requirements of the organization, which in turn reduces job stress. Supervisors should help employees to solve the real problems they are facing, rather than meeting their own or the organizations' other needs. The current study made recommendations that are essential to the advancement of P-O fit research in general. 


\section{References}

Ahsan, N., Abdullah, Z., Fie, D. G. and Alam, S. S. (2009), “A study of job stress on job satisfaction among university staff in Malaysia: Empirical study”, European Journal of Social Sciences, Vol. 8 No. 1, pp. 121-131.

Akien, L. S. and West, S. G. (1991), Multiple regression: Testing and interpreting interactions. Newbury Park, CA:Sage.

Ambrose, M. L., Arnaud, A. and Schminke, M. (2008), "Individual moral development and ethical climate: The influence of person-organization fit on job attitudes”, Journal of Business Ethics, Vol. 77 No. 3, pp. 323-333.

Arthur Jr, W., Bell, S. T., Villado, A. J. and Doverspike, D. (2006), “The use of personorganization fit in employment decision making: An assessment of its criterion-related validity”, Journal of Applied Psychology, Vol. 91 No. 4, pp. 786-801.

Babakus, E., Yavas, U.and Ashill, N. J. (2010), "Service worker burnout and turnover intentions: Roles of person-job fit, servant leadership, and customer orientation”, Services Marketing Quarterly, Vol. 32 No. 1, pp. 17-31.

Bedeian, A. G., Ferris, G. R. and Kacmar, K. M. (1992), “Age, tenure, and job satisfaction: A tale of two perspectives”, Journal of Vocational Behavior, Vol. 40 No. 1, pp. 33-48.

Brotheridge, C. M., \& Lee, R. T. (2002), “Testing a conservation of resources model of the dynamics of emotional labor”. Journal of Occupational Health Psychology, Vol. 7, No.1, pp. 57-67.

Burke, M. J., Borucki, C. C. and Hurley, A. E. (1992), “Reconceptualizing psychological climate in a retail service environment: A multiple-stakeholder perspective”, Journal of Applied Psychology, Vol.77 No. 5, p.717-729. 
Cable, D. M. and DeRue, D. S. (2002), “The convergent and discriminant validity of subjective fit perceptions”, Journal of Applied Psychology, Vol. 87 No. 5, pp. 875-884.

Cennamo, L. and Gardner, D. (2008) , “Generational differences in work values, outcomes and person-organisation values fit”, Journal of Managerial Psychology, Vol. 23 No. 8, pp. 891-906.

Cheng, Y., Luh, W. M. and Guo, Y. L. (2003), "Reliability and validity of the Chinese version of the Job Content Questionnaire in Taiwanese workers”, International journal of Behavioral Medicine, Vol. 10 No. 1, pp. 15-30.

Cooper-Thomas, H. D. and Wright, S. (2013), “Person-environment misfit: the neglected role of social context”, Journal of Managerial Psychology, Vol. 28 No. 1, pp. 21-37.

Cooper-Thomas, H. D., Van Vianen, A. and Anderson, N. (2004), “Changes in personorganization fit: The impact of socialization tactics on perceived and actual P-O fit”, European Journal of Work and Organizational Psychology, Vol. 13 No. 1, pp. 52-78.

Edwards, J. R. (1996), “An examination of competing versions of the person-environment fit approach to stress”. Academy of Management Journal, Vol. 39 No. 2, pp. 292-339.

Eisenberger, R., Armeli, S., Rexwinkel, B., Lynch, P. D. \& Rhoades, L. (2001). Reciprocation of perceived organizational support. Journal of Applied Psychology, Vol. 86, pp. 42-51.

Eisenberger, R., Stinglhamber, F., Vandenberghe, C., Sucharski, I. L. and Rhoades, L. (2002), “Perceived supervisor support: contributions to perceived organizational support and employee retention”, Journal of Applied Psychology, Vol. 87 No. 3, pp. 565-573.

Elkin, A. J., \& Rosch, P. J. (1989), "Promoting mental health at the workplace: the prevention side of stress management”. Occupational Medicine (Philadelphia, Pa.), Vol. 5 No. 4, pp. 739-754. 
Erdogan, B. and Enders, J. (2007), “Support from the top: supervisors' perceived organizational support as a moderator of leader-member exchange to satisfaction and performance relationships”, Journal of Applied Psychology, Vol. 92 No. 2, pp. 321-330.

Erdogan, B., Kraimer, M. L., and Liden, R. C. (2004), "Work value congruence and intrinsic career success: the compensatory roles of leader-member exchange and perceived organizational support”. Personnel Psychology, Vol. 57 No. 2, pp. 305-332.

Eulberg, J. R., Weekley, J. A. and Bhagat, R. S. (1988), "Models of stress in organizational research: A metatheoretical perspective”, Human Relations, Vol. 41 No. 4, pp.331-350.

George, J. M. (1992), “The role of personality in organizational life: Issues and evidence”, Journal of Management, Vol. 18 No. 2, pp. 185-213.

Hobfoll, S.(2002), “Social and psychological resources and adaptations”, Review of General Psychology, Vol.6 No.4, 307-324.

Hobfoll, S. E. (2001), “The influence of culture, community, and the nested-self in the stress process: advancing conservation of resources theory”, Applied Psychology, Vol. 50 No. 3, pp.337-421.

Hoffman, B. J. and Woehr, D. J. (2006), “A quantitative review of the relationship between person-organization fit and behavioral outcomes”, Journal of Vocational Behavior, Vol. 68 No. 3, pp. 389-399.

Hutchison, S., Sowa, D., Eisenberger, R. and Huntington, R. (1986), "Perceived organizational support”, Journal of Applied Psychology, Vol. 71 No. 3, pp. 500-507.

Janssen, O. and Van Yperen, N. W. (2004), “Employees' goal orientations, the quality of leader-member exchange, and the outcomes of job performance and job satisfaction”, Academy of management journal, Vol. 47 No. 3, pp. 368-384. 
Karasek, R., Brisson, C., Kawakami, N., Houtman, I., Bongers, P., \& Amick, B. (1998), “The Job Content Questionnaire (JCQ): an instrument for internationally comparative assessments of psychosocial job characteristics”. Journal of Occupational Health Psychology, Vol. 3 No. 4, pp. 322-355.

Klassen, R. M., Usher, E. L. and Bong, M. (2010), “Teachers' collective efficacy, job satisfaction, and job stress in cross-cultural context”, The Journal of Experimental Education, Vol. 78 No. 4, pp.464-486.

Kottke, J. L. and Sharafinski, C. E. (1988), "Measuring perceived supervisory and organizational support”, Educational and Psychological Measurement, Vol. 48 No. 4, pp.1075-1079.

Kristof, A. L. (1996), "Person-organization fit: An integrative review of its conceptualizations, measurement, and implications”, Personnel Psychology, Vol. 49 No. 1, pp.1-49.

Kristof-Brown, A. L., Zimmerman, R. D. and Johnson, E. C. (2005), "Consequences of individuals' fit at work: a meta-analysis of person-job, person-organization, persongroup, and person-supervisor fit”, Personnel Psychology, Vol. 58 No. 2, pp.281-342.

Lee, R. T. and Ashforth, B. E. (1996), “A meta-analytic examination of the correlates of the three dimensions of job burnout”, Journal of Applied Psychology, Vol. 81 No. 2, p.123133.

Li, C.P. (2003), “Transformational leadership: dimension, measurement and its mechanism” (Doctoral Dissertation), Chinese Academy of Sciences, Beijing (in Chinese).

Liu, B., Liu, J., \& Hu, J. (2010), "Person-organization fit, job satisfaction, and turnover intention: an empirical study in the Chinese public sector”. Social Behavior and Personality: an International Journal, Vol. 38 No. 5, pp. 615-625. 
Lok, P. and Crawford, J. (2004), “The effect of organisational culture and leadership style on job satisfaction and organisational commitment: A cross-national comparison”, Journal of Management Development, Vol. 23 No. 4, pp. 321-338.

Muller, D., Judd, C. M., \& Yzerbyt, V. Y. (2005), "When moderation is mediated and mediation is moderated”. Journal of Personality and Social Psychology, Vol. 89 No. 6, pp. 852-863.

Nadiri, H. and Tanova, C. (2010), “An investigation of the role of justice in turnover intentions, job satisfaction, and organizational citizenship behavior in hospitality industry”, International Journal of Hospitality Management, Vol. 29 No. 1, pp.33-41.

O'Reilly, C. A., Chatman, J. and Caldwell, D. F. (1991), “People and organizational culture: A profile comparison approach to assessing person-organization fit”, Academy of Management Journal, Vol. 34 No. 3, pp. 487-516.

Papadopoulou-Bayliss, A., Ineson, E. M., \& Wilkie, D. (2001), “Control and role conflict in food service providers”. International Journal of Hospitality Management, Vol. 20 No. 2, pp. 187-199.

Park, H., Monnot, M. J., Jacob, A. C. and Wagner, S. H. (2011), "Moderators of the relationship between person-job fit and subjective well-being among Asian employees”, International Journal of Stress Management, Vol. 18 No. 1, pp. 67-87.

Parker, D. F. and DeCotiis, T. A. (1983), “Organizational determinants of job stress”, Organizational Behavior and Human Performance, Vol. 32 No. 2, pp.160-177.

Peng, J., Lee, Y. and Tseng, M. (2014), “Person-organization fit and turnover intention: exploring the mediating effect of work engagement and the moderating effect of demand-ability fit”, The Journal of Nursing Research, Vol. 22 No. 1, pp.1-11.

Podsakoff, P. M., MacKenzie, S. B., Lee, J. Y. and Podsakoff, N. P. (2003), “Common 
method biases in behavioral research: a critical review of the literature and recommended remedies”, Journal of Applied Psychology, Vol. 88 No. 5, pp. 879-903.

Preacher, K. J., \& Hayes, A. F. (2008). Asymptotic and resampling strategies for assessing and comparing indirect effects in multiple mediator models. Behavior Research Methods, Vol. 40 No. 3, pp. 879-891.

Preacher, K. J., Rucker, D. D., \& Hayes, A. F. (2007). Assessing moderated mediation hypotheses: Theory, methods, and prescriptions. Multivariate Behavioral Research, Vol. 42, pp. 185-227.

Resick, C. J., Baltes, B. B. \& Shantz, C. W. (2007), “Person-organization fit and work-related attitudes and decisions: Examining interactive effects with job fit and conscientiousness”, Journal of Applied Psychology, Vol. 92 No. 5, p. 1446-1455.

Rhoades, L. \& Eisenberger, R. (2002). Perceived organizational support: A review of the literature. Journal of Applied Psychology, Vol. 87, pp. 698-714.

Siemsen, E., Roth, A. and Oliveira, P. (2010), “Common method bias in regression models with linear, quadratic, and interaction effects”, Organizational Research Methods, Vol. 13 No. 3, pp.456-476.

Silverthorne, C. (2004), “The impact of organizational culture and person-organization fit on organizational commitment and job satisfaction in Taiwan”, Leadership \& Organization Development Journal, Vol. 25 No. 7, pp.592-599.

Tett, R. P. and Meyer, J. P. (1993), “Job satisfaction, organizational commitment, turnover intention, and turnover: path analyses based on meta-analytic findings”, Personnel Psychology, Vol. 46 No.2, pp.259-293.

Tsui, A. S., Egan, T. and O'Reilly, C. (1991), “Being different: Relational demography and organizational attachment”, Academy of Management Proceedings, Vol. 1991 No. 1, pp. 
183-187.

Vancouver, J. B. and Schmitt, N. W. (1991), “An exploratory examination of personorganization fit: Organizational goal congruence”, Personnel Psychology, Vol. 44 No. 2, pp. 333-352.

Verquer, M. L., Beehr, T. A. and Wagner, S. H. (2003), “A meta-analysis of relations between person-organization fit and work attitudes”, Journal of Vocational Behavior, Vol. 63 No. 3, pp. 473-489.

Viswesvaran, C., Sanchez, J. I. and Fisher, J. (1999), "The role of social support in the process of work stress: A meta-analysis”, Journal of Vocational Behavior, Vol. 54 No. 2, pp.314-334.

Westerman, J. W. and Cyr, L. A. (2004), “An integrative analysis of person-organization fit theories”, International Journal of Selection and Assessment, Vol. 12 No.3, pp.252-261.

Zhong, W. and Lin, Z. (2010), “An Empirical Study on Relations among Person-Organization Fit, Job Satisfaction and Turnover Intention”, Chinese Journal of Management, Vol. 7 No. 3, pp.379-385. (in Chinese) 


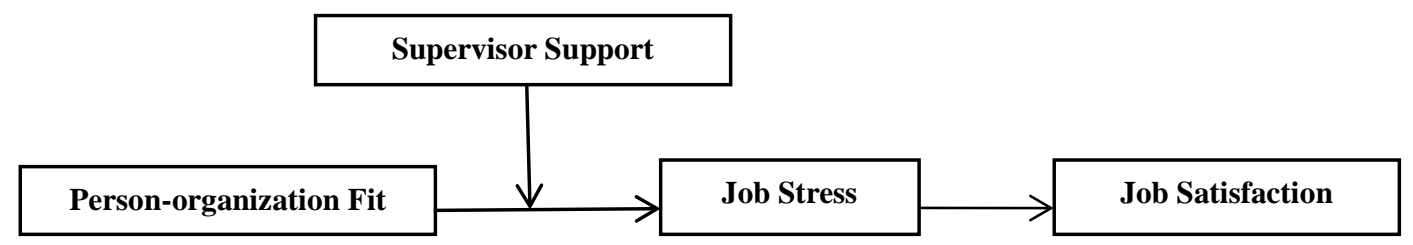

Figure 1. Research model diagram 


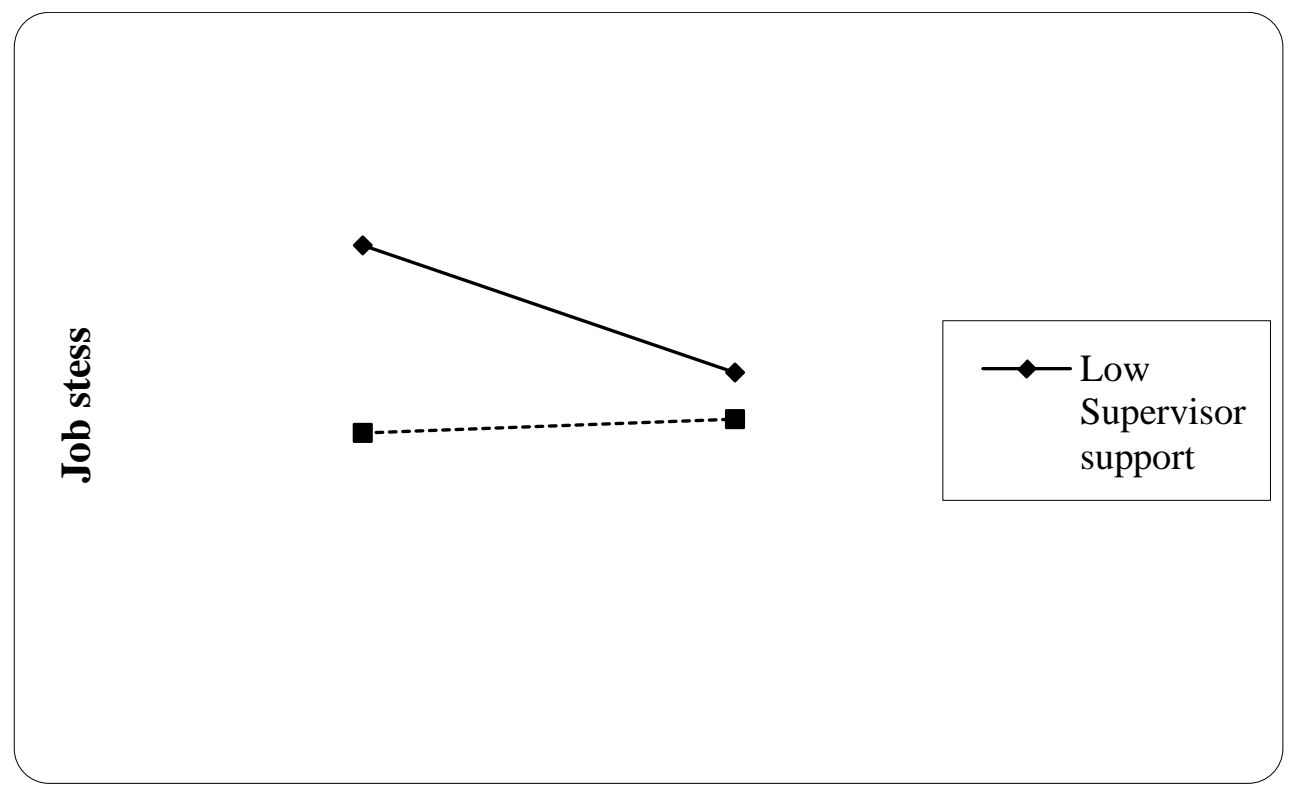

Figure 2. The moderation effect of supervisor support (Moderator) between P-O fit (IV) and job stress (DV) 
Table 1. Means, standard deviations, and correlations of research variables

\begin{tabular}{|c|c|c|c|c|c|c|c|c|c|c|}
\hline Variables & M & $\mathrm{SD}$ & 1 & 2 & 3 & 4 & 5 & 6 & 7 & 8 \\
\hline 1.Gender & 1.67 & 0.47 & & & & & & & & \\
\hline 2.Age & 1.57 & 0.72 & -0.04 & & & & & & & \\
\hline 3.Education & 2.30 & 1.21 & -0.10 & -0.04 & & & & & & \\
\hline 4.Tenure & 1.90 & 1.16 & 0.13 & 0.07 & -0.03 & & & & & \\
\hline 5.Supervisor support & 4.71 & 0.88 & -0.02 & -0.10 & -0.08 & -0.06 & $(0.82)$ & & & \\
\hline 6.Job satisfaction & 4.05 & 1.02 & 0.01 & -0.00 & $-0.26^{* *}$ & -0.13 & $0.51^{* *}$ & $(0.85)$ & & \\
\hline 7.Job stress & 3.49 & 0.91 & 0.09 & 0.10 & $0.17^{*}$ & $0.19^{* *}$ & $-0.24 * *$ & $-0.43^{* *}$ & $(0.86)$ & \\
\hline 8.P-O fit & 3.91 & 0.81 & 0.06 & -0.02 & -0.03 & -0.01 & $0.38 * *$ & $0.42 * *$ & $-0.19 * *$ & $(0.83)$ \\
\hline
\end{tabular}

Notes: $\mathrm{n}=225$.Tenure was measured by the tenure with the current immediate supervisor. The reliability coefficients appear in parentheses along the main diagonal. ${ }^{*} p<0.05,{ }^{* *} p<$ 0.01 (2-tailed) 
Table 2 . Bootstrapping with moderated mediation model

\begin{tabular}{|c|c|c|c|c|c|c|}
\hline Variable & $B$ & $S E$ & $t$ & $P$ & $L L C I$ & $U L C I$ \\
\hline \multicolumn{7}{|c|}{ Mediator variable model with job stress as dependent variable } \\
\hline Constant & -0.45 & 0.21 & -2.10 & 0.04 & -1.87 & -0.03 \\
\hline P-O fit & -0.09 & 0.08 & -1.18 & 0.24 & -0.25 & 0.06 \\
\hline Supervisor support & -0.19 & 0.07 & -2.61 & 0.01 & -0.34 & -0.05 \\
\hline Interaction variable (P-O fit $\times$ Supervisor support) & 0.12 & 0.07 & 1.71 & 0.08 & -0.02 & 0.25 \\
\hline Gender & 0.25 & 0.12 & 2.03 & 0.04 & 0.01 & 0.49 \\
\hline Age & 0.04 & 0.08 & 0.51 & 0.61 & -0.12 & 0.20 \\
\hline Education & 0.13 & 0.05 & 2.62 & 0.01 & 0.03 & 0.22 \\
\hline Tenure & 0.11 & 0.05 & 2.18 & 0.03 & 0.01 & 0.21 \\
\hline \multicolumn{7}{|c|}{ Dependent variable model with job satisfaction as dependent variable } \\
\hline Constant & 4.24 & 0.29 & 14.65 & 0.00 & 3.67 & 4.81 \\
\hline Job stress & -0.39 & 0.07 & -6.03 & 0.00 & -0.52 & -0.26 \\
\hline P-O fit & 0.48 & 0.07 & 6.81 & 0.86 & 0.34 & 0.61 \\
\hline Gender & 0.05 & 0.12 & 0.41 & 0.00 & -0.19 & 0.29 \\
\hline Age & 0.04 & 0.08 & 0.51 & 0.56 & -0.12 & 0.20 \\
\hline Education & -0.12 & 0.05 & -2.51 & 0.96 & -0.21 & -0.03 \\
\hline Tenure & -0.03 & 0.05 & -0.62 & 0.77 & -0.13 & 0.07 \\
\hline \multicolumn{7}{|c|}{ Conditional indirect effect as a function of supervisor support } \\
\hline Value of supervisor support & & Effect & Bootse & Boot $L L C I$ & & BootULCI \\
\hline-0.88 & & 0.08 & 0.03 & 0.01 & & 0.14 \\
\hline 0.00 & & 0.04 & 0.03 & -0.02 & & 0.10 \\
\hline 0.88 & & -0.00 & 0.04 & -0.08 & & 0.09 \\
\hline
\end{tabular}

